BMJ Open

Sport \&

Exercise

Medicine

\title{
Complex shoulder girdle injuries following mountain bike accidents and a review of the literature
}

\author{
Matthew Alexander Lea, ${ }^{1}$ Navnit Makaram, ${ }^{2}$ Makaram S Srinivasan ${ }^{1}$
}

To cite: Lea MA, Makaram N, Srinivasan MS. Complex shoulder girdle injuries following mountain bike accidents and a review of the literature. BMJ Open Sport Exerc Med 2016;2: 000042. doi:10.1136/bmjsem-2015000042

- Prepublication history for this paper is available online To view these files please visit the journal online (http://dx.doi.org/10.1136/ bmjsem-2015-000042).

Accepted 19 November 2015

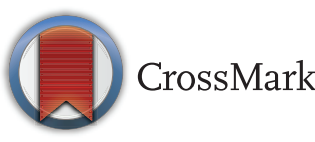

${ }^{1}$ Orthopaedic Department, Royal Blackburn Hospital, Blackburn, UK

${ }^{2}$ Orthopaedic Department, NHS Tayside, Dundee, UK

Correspondence to Dr Matthew Alexander Lea; matthewlea@doctors.org.uk

\section{ABSTRACT}

Background: Mountain and road bike accidents are particularly common with the increased popularity of the sport. We reviewed the attendances in our emergency department over a 4-year period looking at cycling injuries to detect the level and grade of these injuries and their outcomes.

Method: Royal Blackburn Hospital caters for a population of 550000 . A search through the Hospital information system revealed 104 patients with fractures following mountain bike injuries. These were looked at in more detail. We present a series of 5 severe shoulder girdle injuries following mountain bike accidents in this cohort, to highlight the serious level of injury sustained in this sport. We searched MEDLINE and EMBASE databases over the past 10 years using the keywords, mountain, biking and fracture. This yielded 7 papers. We compared our series with the literature.

Results: 104 fractures following mountain bike accidents between 2008 and 2011. Fractures of the upper limb were the most common $(88.5 \%)$ with the clavicle being the most commonly fractured bone (28.8\%).

Conclusions: Major scapular injuries with destruction or disruption of the four bar linkage of the shoulder girdle are very common following mountain accidents. Clavicular fractures are the commonest upper limb injury. It is easy to miss a disruption to the four-bar linkage associated with a clavicular injury. This paper highlights the severity of the injuries sustained in mountain bike accidents of the upper limb and requirement of adequate protection in this exhilarating sport.

\section{INTRODUCTION}

The incidence of orthopaedic injuries associated with mountain bike accidents has increased over the past 10 years, as the popularity of this exhilarating, adrenaline-filled nature-based activity is the key driver for this sport. Tourism intelligence Scotland \& International Mountain Biking Association (IMBA) reported in 2007, that 11.8 million people owned a mountain bike in the UK. The economic value of tourism in mountain
What are the new findings?

- Mountain biking accidents can result in serious injuries to the shoulder girdle affecting the four-bar linkage.

- Upper limb injuries are the most common following mountain bike accidents.

- We outline successful surgical management of some of these injuries.

biking in Scotland alone has shown figures of around $£ 46.5$ million annual spend, with indirect expenditure of around $£ 119$ million. The most popular mountain biking centres attracting nearly 400000 visitors per year in 2007 and an expected increase of 5\% every year or more. With the rising popularity of the sport, an increasing number of enthusiasts are involved in exploring new, exciting but treacherous terrain. ${ }^{1-5}$ We aimed to review the incidence and produce a breakdown of orthopaedic injuries related to this sport at a regional district general hospital in North of England, that serves a population of 550000 . This enabled us to report in greater detail on patients sustaining complex injuries of the shoulder girdle, involving disruption to the four-bar linkage consisting of disruption of the bony-soft tissue ring of structures namely, clavicle, coracoclavicular ligaments and coracoid linkage (figure 1A).

The superior shoulder suspensory complex (SSSC) consists of 'bony-soft tissue ring' at the end of bony struts of the superior aspect of the glenoid process, the coracoid process, the distal clavicle and the acromion process with the soft issue elements connecting them, the coracoclavicular ligaments, the acromioclavicular ligaments with the acromioclavicular joint. ${ }^{6-8}$ Goss and Busconi have illustrated the three components of SSSC (figure 1B)..$^{7}$ They consist of (1) the clavicle, A-C joint and acromial strut; (2) the clavicle, coracoclavicular ligaments and coracoid strut, and so-called C-4 
Figure 1 (A) Anatomy of the superior shoulder suspensory complex (SSSC). (B) The three components of SSSC. (C) Complex shoulder girdle injuries with single (type I) and double (type II) disruptions.
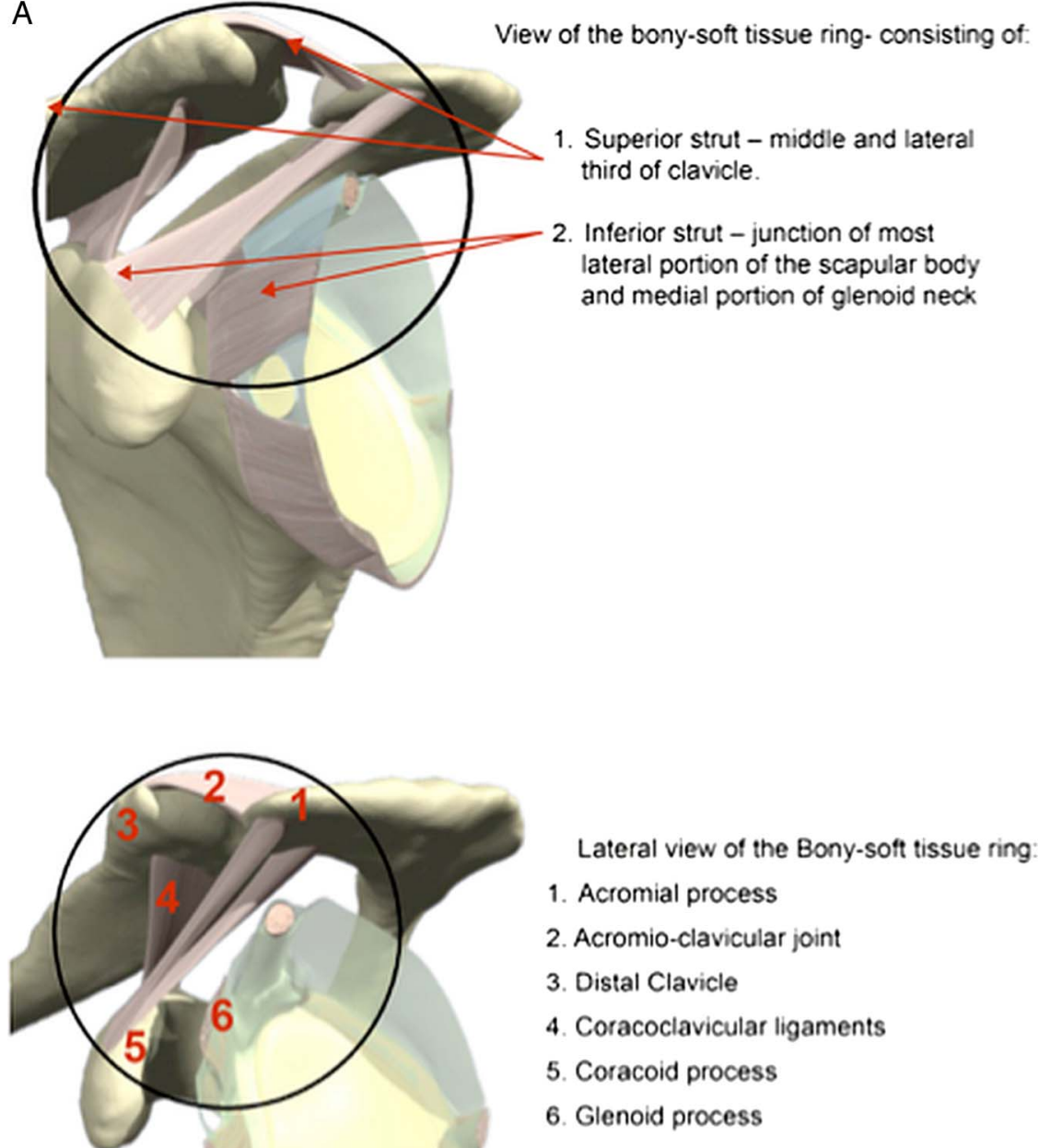

linkage and (3) the three processes of Acromion, coracoid and glenoid scapular body junction. ${ }^{8}$

Goss suggested that injuries involving SSSC with a single disruption can be treated non-operatively and are usually stable. An injury resulting in double disruption of SSSC can make the other part of the ring unstable. Hardeggar et al and Butters have both consider such injuries with double disruption of the ring to represent a functional imbalance and recommend surgical intervention to stabilise at least one of the components of the ring. ${ }^{8}$

For this study we followed the classification system by the senior author (figure 1C) based on the studies by Goss, Hardeggar and Butlers: ${ }^{8}$

- Type I: Any single disruption of SSSC, depending on the displacement could be treated non-operatively.

- Type II: Any double disruption of SSSC, is complex injury of the shoulder girdle and is an indication for surgery.

This paper aims to show the incidence of orthopaedic mountain bike injuries at a busy district general hospital and look in further detail at injuries involving the four-bar linkage.

\section{METHOD}

We contacted the clinical information department at our trust and through the use of clinical coding were able to identify all patients attending the emergency department (ED) with a fracture between 2008 and 2011. Our hospital coding does record the mechanism of injury, for example, cycling injury, RTA, skating, etc. Road cycling injuries are jointly coded under RTA and cycling injury, these were excluded. As the information had been coded prior to review we are relying on this being coded correctly. We then refined this search by isolating those patients with cycling injuries not related to the roads. The information on these patients was examined in closer detail. Paediatric patients ( $<16$ years), isolated soft tissue injuries and nonmountain bike accidents (such as road traffic accidents), were excluded. Of the remaining patients, all patients with fractures sustained from cycling were reviewed closely. Accident and emergency notes were scanned for mountain bike accidents with severe upper limb injuries, involving double disruption to SSSC. Only five were identified as having a complex injury to the shoulder, which we defined as a shoulder girdle injury with 


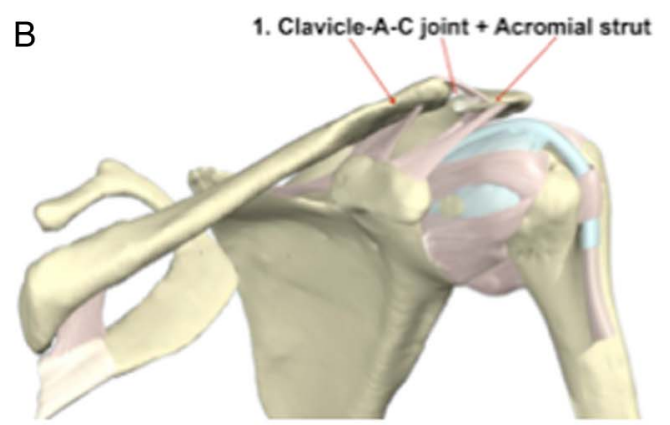

2. Coraco-clavicular ligaments + coraco-acromial ligaments + corocoid linkage- "C-4 linkage"

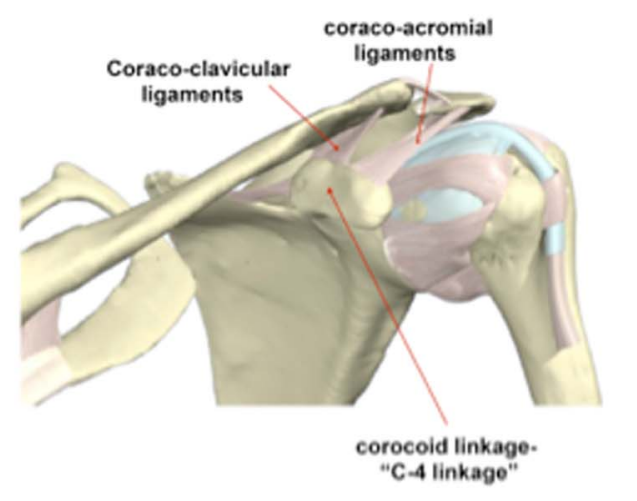

3. Corocoid process + Acromion process + scapular body junction

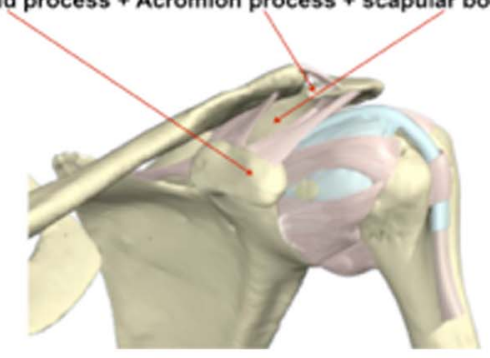

C Soft Tissue/Bony Ring

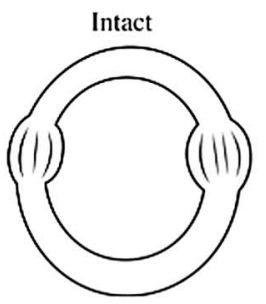

Single distruptions

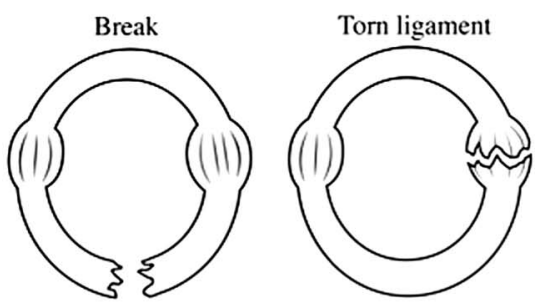

Double distruptions
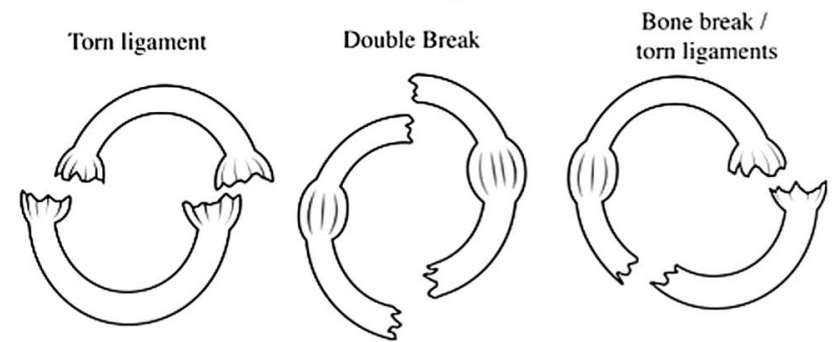

disruption to the four-bar linkage, as type II injuries defined by the senior author.

We followed up the five patients identified above. Patient notes in combination with a questionnaire were used in which we asked the patients to provide information relating to the following: occupation, dominant hand, date of injury, mechanism of injury, type of injury sustained, treatment (operative or conservative), the time period until they were cycling again, residual pain on a scale of $0-10$ (10 being the worst pain and 0 being pain free) and how long the patient was absent from work. We approached the local regional Research Governance team and the paper was considered to be level 4 study and a short case series. All ethical requirements of individual patients' consent forms were obtained including NHS consent. This was deemed satisfactory as per the local committee.

For our literature search we used PubMed, MEDLINE and EMBASE databases, the following keywords we used in our search: mountain biking, injuries, shoulder girdle injuries and upper limb injuries.

\section{RESULTS}

Over a 4-year period there were 28774 attendances at our ED for fractures. Of these, 261 were related to bicycles. This group of patients was studied in further detail and the exclusion criteria were applied. This resulted in 104 fractures from mountain bike accidents over a 4-year period. The mean age of our 104 patients was 38.4 years. Our analysis showed that fractures of the upper limb following mountain bike accidents were the most common $(88.5 \%)$ and that the clavicle was the most common bone injured (28.8\%), with lower limb and axial injuries being relatively uncommon. The results are summarised in tables 1 and 2 .

The literature search yielded a total of 83 publications. Following review of the abstracts seven articles were deemed to fit the inclusion criteria. Inclusion criteria were: adult papers, mountain biking only and musculoskeletal injuries.

We studied five patients in further detail who had sustained shoulder girdle injuries after falls from a mountain bike. The average age of these patients at the time of injury was 43 years (34-51).

Patient $A$ was a 51-year-old, right-handed, male shop owner who sustained a fracture of the right coracoid and acromion. The accident happened while he was travelling downhill at speed and then hit a rock. He was thrown over the handlebars and landed with outstretched arms with force of the impact on the head of the right humerus. A CT scan on arrival at hospital revealed a comminuted fracture through the body of the acromion process with an $8 \mathrm{~mm}$ separation of the fracture fragments. The acromioclavicular (AC) joint was not involved and remained in normal alignment. An additional comminuted minimally

Figure 1 Continued. 
Table 1 Trend in emergency department attendance for fractures

\begin{tabular}{lllll}
\hline Year & $\mathbf{2 0 0 8}$ & $\mathbf{2 0 0 9}$ & $\mathbf{2 0 1 0}$ & $\mathbf{2 0 1 1}$ \\
\hline Fracture attendances & 7184 & 7536 & 6926 & 7128 \\
\hline
\end{tabular}

displaced fracture was present involving the scapular blade/body and extending through the base of the coracoid process. It did not extend to involve any significant proportion of the articular surface. This was a shoulder girdle/suspensory complex disruption-type D: double break. $^{6}$

The coracoid was fixed with a single cannulated screw. A five-hole recon plate was used to stabilise the acromion. The patient spent 9 weeks in a polysling and he was cycling again 4 months after his operation. At 9 months postoperatively he had no symptoms of any residual pain, citing $0 / 10$. He was absent from work for 2 days postdischarge. A CT scan at 7 months postoperatively showed slow bony union of the fracture sites. The injury and management are demonstrated in figure 2A, B.

Patient $B$ was a 46-year-old, left-handed, male office worker who sustained a fracture of the right glenoid. The accident occurred while he was cycling downhill at speed and hit a rock. He passed over the handlebars and landed on his right outstretched arm. He sustained a vertically orientated fracture involving approximately $40 \%$ of the joint surface with about $10 \mathrm{~mm}$ of joint depression. This was an Ideberg type IV injury. ${ }^{9}$

Two cannulated screws were used to fix the fragment. He spent 6 weeks in a sling and was cycling again 13 weeks postoperatively. He reported very little pain $(0 / 10) 2$ years after his operation, but he did note a few episodes of discomfort on hyperextension of the shoulder. He returned to work 6 weeks after discharge. A CT scan at 2 years postoperatively showed complete healing of the fracture (figure $3 \mathrm{~A}, \mathrm{~B}$ ).

Patient $C$ was a 41-year-old, right-handed, male office worker who had an undisplaced fracture of the greater tuberosity of the right humerus. The accident occurred when he was cycling downhill and tried to jump over a puddle; the bike landed incorrectly and he fell over the handlebars landing on a flexed right elbow.

This fracture was treated conservatively with a polysling for 6 weeks. After discharge he was still in some discomfort scoring 3/10. Despite this pain there was no restriction in the range of movement 3 years after the fracture. He was away from work for 2 weeks and was cycling again 12 weeks after the injury. A CT scan at 3 years postinjury showed mild osteoarthritic changes at the right glenohumeral and AC joint as seen in figure 4.

Patient $D$ was a 43-year-old right-handed machine operator. He was cycling downhill at approximately $30 \mathrm{mph}$ and tried to jump a gap, which he misjudged and missed. His right arm was outstretched and took the full force of the fall. He did not come off his bike. He dislocated his right shoulder and fractured the right scapula.
Table 2 Trend in fractures relating to mountain bike injuries and fracture location

\begin{tabular}{lrrrrr}
\hline & $\mathbf{2 0 0 8}$ & $\mathbf{2 0 0 9}$ & $\mathbf{2 0 1 0}$ & $\mathbf{2 0 1 1}$ & Total \\
\hline Upper limb & & & & & \\
$\quad$ Clavicle & 7 & 7 & 5 & 10 & 29 \\
Scapula & 0 & 1 & 2 & 2 & 5 \\
Humerus & 2 & 0 & 2 & 1 & 5 \\
Radial head & 2 & 0 & 3 & 6 & 11 \\
Distal radius & 1 & 3 & 4 & 6 & 14 \\
Ulna & 0 & 2 & 3 & 1 & 6 \\
Metacarpals & 1 & 2 & 2 & 7 & 12 \\
Phalanges & 2 & 1 & 3 & 4 & 10 \\
$\quad$ Subtotal & 15 & 16 & 24 & 37 & 92 \\
Lower limb & & & & & \\
Femur & 0 & 0 & 0 & 1 & 1 \\
Tibia and fibula & 0 & 0 & 0 & 1 & 1 \\
Ankle & 1 & 0 & 2 & 1 & 4 \\
Phalanges & 0 & 0 & 1 & 0 & 1 \\
$\quad$ Subtotal & 1 & 0 & 3 & 3 & 7 \\
Axial & & & & & \\
Lumbar spine & 1 & 0 & 0 & 0 & 1 \\
Pelvis & 1 & 0 & 2 & 0 & 3 \\
$\quad$ Ribs & 0 & 0 & 0 & 1 & 1 \\
$\quad$ Subtotal & 2 & 0 & 2 & 1 & 5 \\
Total & 18 & 16 & 29 & 41 & 104 \\
\hline
\end{tabular}

His shoulder was reduced in a local ED and he attended our unit for open reduction internal fixation of his right scapula (figure 5). He used a sling for 8 weeks, after which he returned to sport. He was back at work after 13 weeks. He had no residual pain from the injury but there was some restriction of movement at 2 years postinjury. At this time he was unable to abduct past $150^{\circ}$. All other movements were normal.

Patient $E$ was a 34 -year-old, right-handed engineer. $\mathrm{He}$ was cycling downhill and while travelling over a jump he hit a banking and the apex of the right shoulder took the full force of the fall. He separated from his bike, which came to rest about $20 \mathrm{~m}$ further down the hill. $\mathrm{He}$ sustained a dislocation of the right $\mathrm{AC}$ joint.

The joint was operated and a plate and screws were inserted to reduce the dislocation. It was a Rockwood grade IV injury. ${ }^{10}$ He was placed in a sling for 5 weeks and was back at work 1 week postoperatively on light duties. He returned to cycling 6 weeks after his second operation (the removal of the plate). He had no symptoms of restriction of movement in the right shoulder. There was some aching in the joint whenever he lay on the shoulder for a long period of time $(2 / 10)$. Otherwise he remained pain free. All five of our patients' injuries are summarised in table 3 .

CT images were done in all patients and MRI was used in some to detect soft tissue disruption and included in the above analysis of the classification of shoulder girdle fractures.

The age group most likely to be injured is 30 39 years. ${ }^{2}$ We found that complex injuries to the 
Figure 2 Patient A: (A)

preoperative and $(B)$

postoperative fixation images.
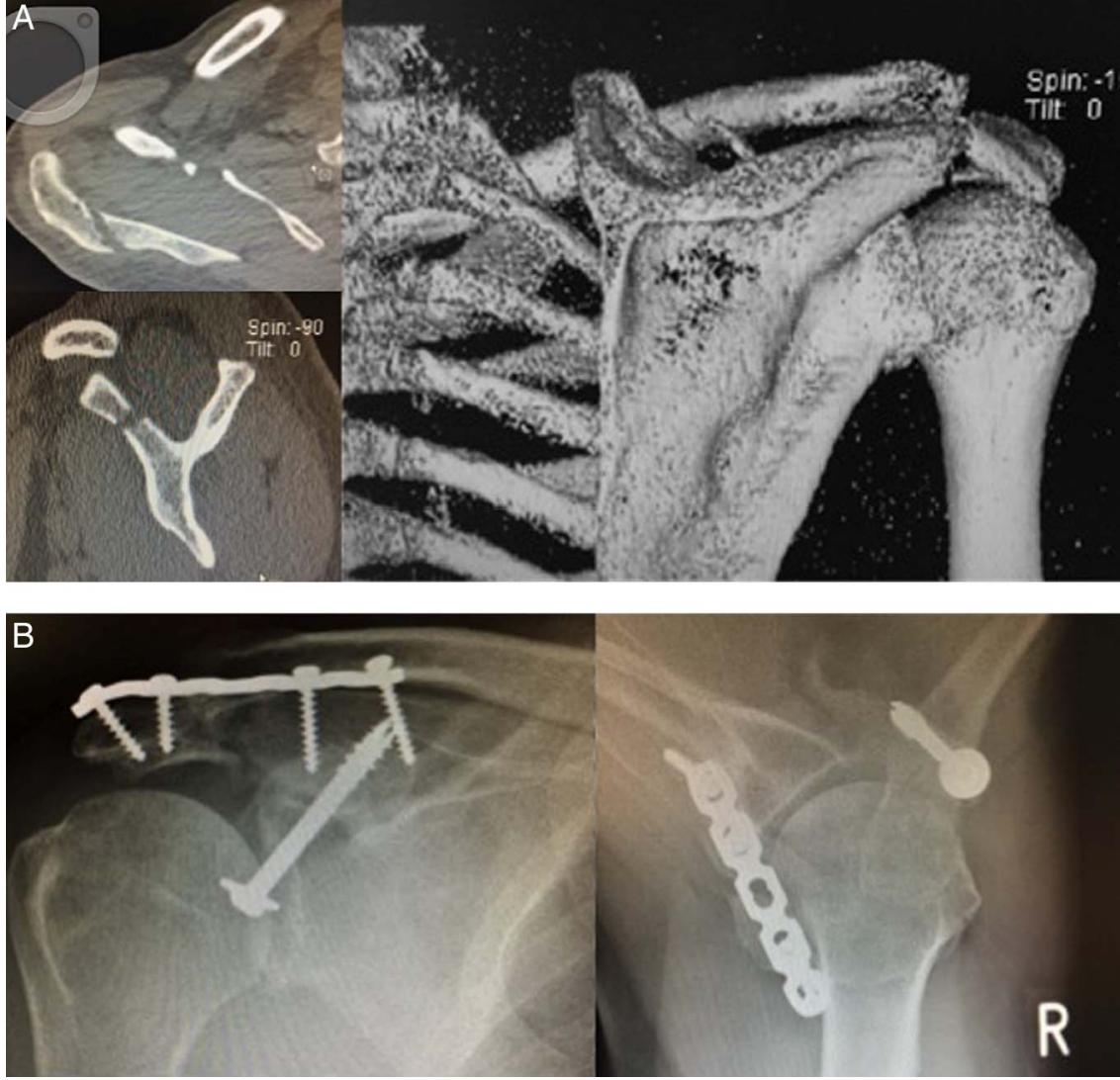

shoulder girdle involving disruption of the four-bar linkage were more common in older cyclists.

\section{DISCUSSION}

Our five patients were older than the average age for mountain bike injuries in our centre. Apart from patient $\mathrm{C}$, they had good results and have regained full pain-free functionality following their operations. Patient C had problems with discomfort and pain postinjury and was the only member of the group who was treated non- operatively. He was the youngest of our patients and his follow-up CT scan was the only one that showed osteoarthritic changes in the joint.

All of our patients sustained their injuries having been thrown over the handlebars, which is in keeping with the current literature as the most common mechanism of injury. They all sustained upper limb fractures/dislocations, which have been noted as the most common type of fracture in this type of accident. The average period for return to cycling was 14 weeks.
Figure 3 Patient $B:(A)$

preoperative and $(B)$

postoperative images.

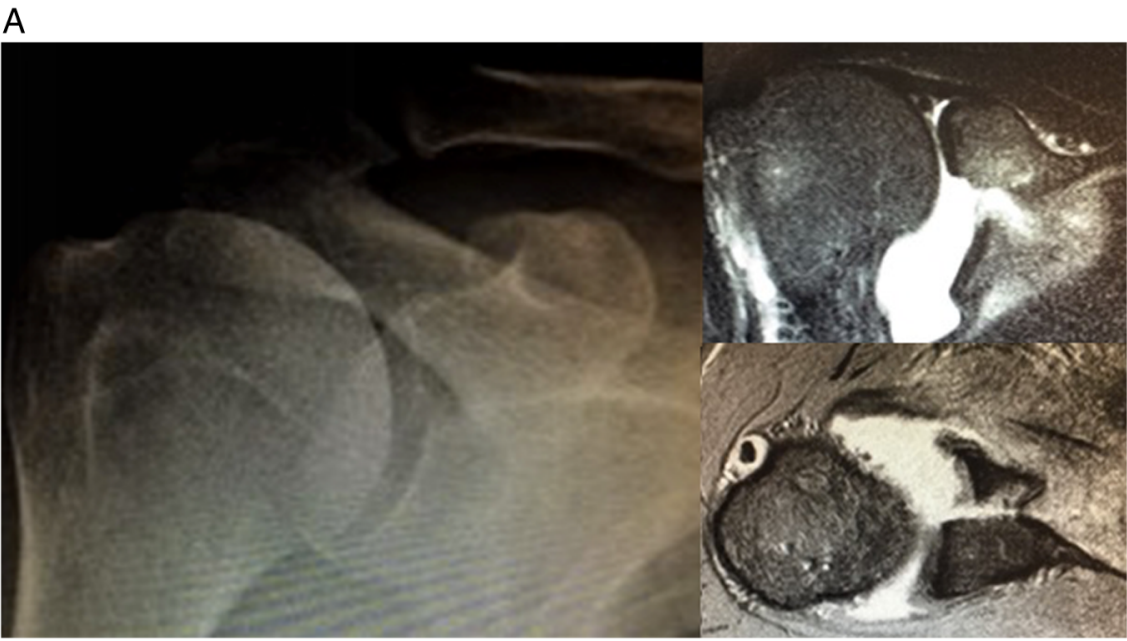


Figure 3 Continued.

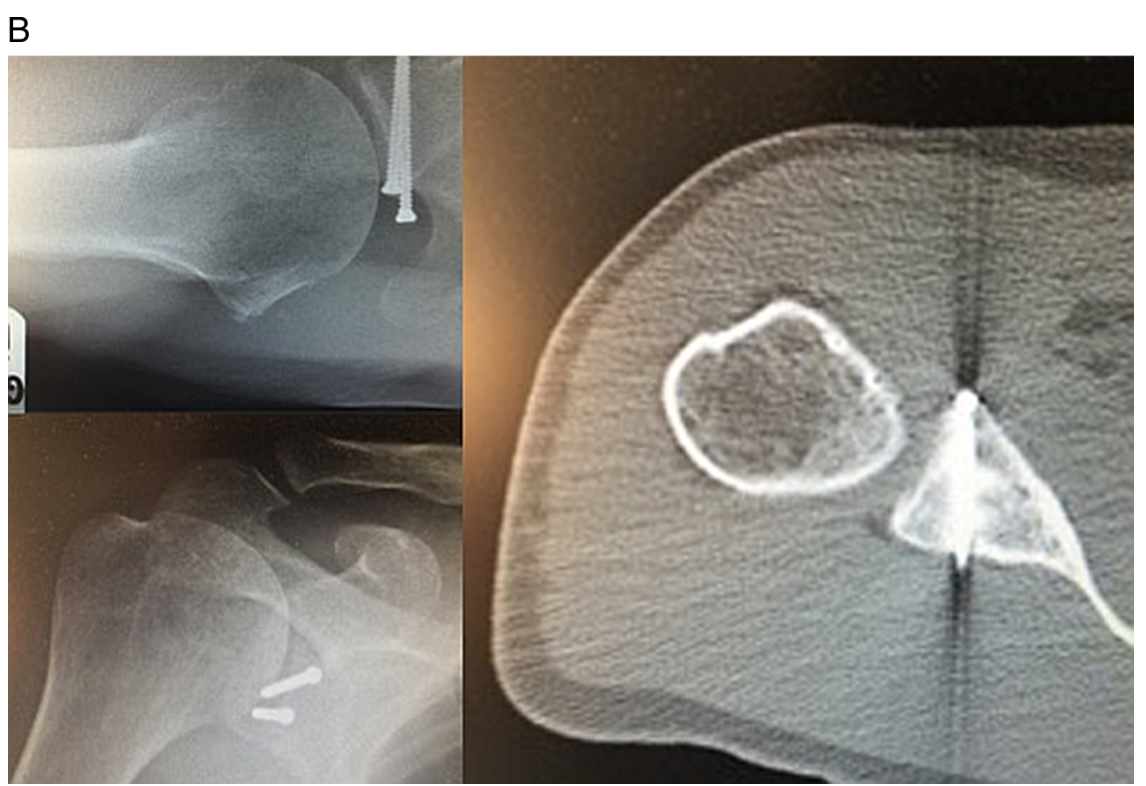

Mountain biking as a sport is increasing in popularity, and men between the ages of 20 and 39 years are most likely to be injured while participating. ${ }^{1}$ Being thrown over the handlebars following sudden deceleration is the most common mechanism of injury and has the most serious results. ${ }^{4}$ Most papers agree that orthopaedic injuries are the most commonly sustained, ${ }^{3-5}$ including fractures and soft tissue injuries. Of the upper limb fractures, fractures of the clavicle is the most common. ${ }^{11}$ Other common fracture sites include: the radial head, distal radius, scaphoid, metacarpals and phalanges. ${ }^{4}$ The most common dislocation is at the AC joint. ${ }^{1}{ }^{4}$ More injuries are sustained in downhill biking than crosscountry, this may be due to the higher speeds achieved.

Other papers suggest that the best way to reduce injury is to use proper equipment, wear a helmet and only ride within your skill level. ${ }^{1-4}$

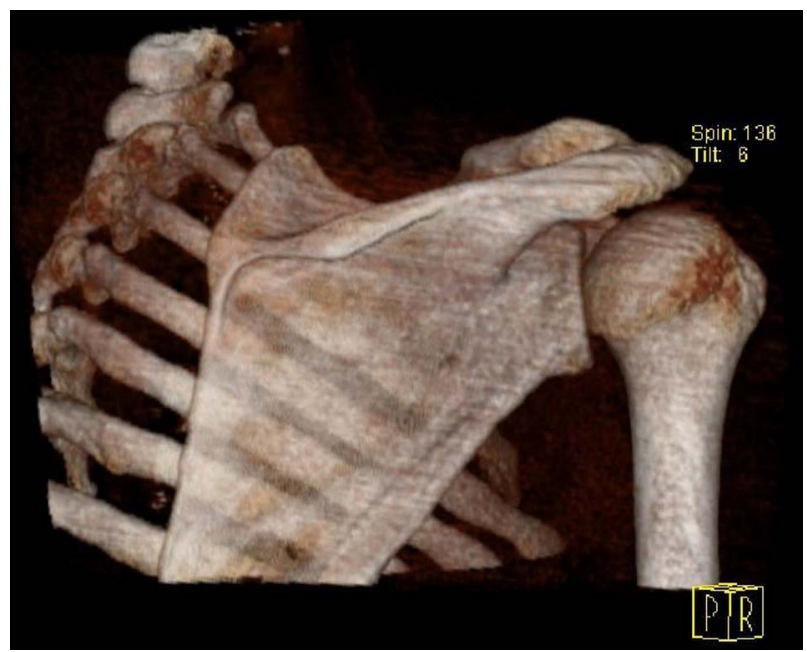

Figure 4 Three-dimensional reconstruction of the shoulder of patient $\mathrm{C}$ following injury.
Riders are quick to adopt safety measures. Helmet usage is now increasingly common and handlebar adaptations have been discontinued. Although the sport has a reputation for speed and risk, with research and awareness, injury prevention measures are being adopted to improve safety.

No previous papers have reviewed surgical intervention of fractures or orthopaedic management of the patient group sustaining fractures.

Our data suggested that mountain bike injuries as a whole are becoming increasingly common. This is in agreement with current literature. ${ }^{1} 4{ }^{11}$ Enthusiasm within the sport and its popularity have encouraged a greater number of middle aged individuals to take up mountain biking, thus resulting in more complex injuries.

\section{CONCLUSION}

Upper limb injuries are the most common type incurred in mountain biking accidents, followed in prevalence by lower limb and head injuries. The age group most likely

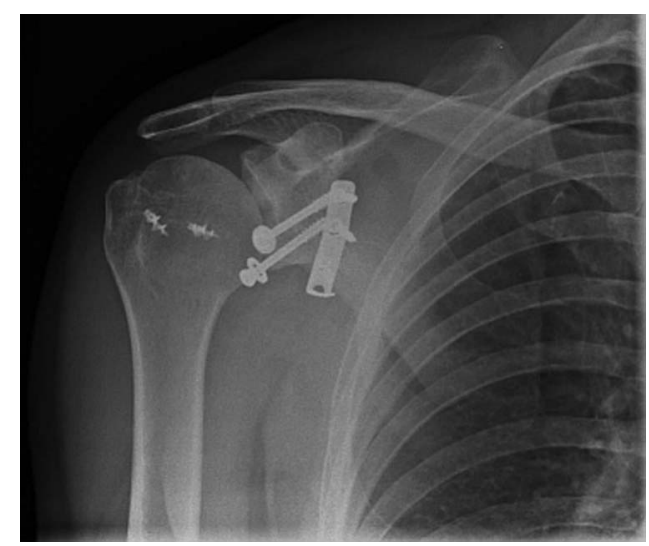

Figure 5 X-ray demonstrating the postoperative fixation of patient $\mathrm{D}$. 
Table 3 Summary of patient injuries

\begin{tabular}{lll}
\hline Patient & $\begin{array}{l}\text { Fracture } \\
\text { classification }\end{array}$ & Injury \\
\hline A & Type D (Goss) & $\begin{array}{l}\text { Fractured the right coracoid } \\
\text { and acromion. Traumatic } \\
\text { shoulder girdle/suspensory } \\
\text { complex disruption-type D: } \\
\text { double break } \\
\text { Transverse fracture through } \\
\text { the glenoid fossa exiting } \\
\text { through the medial border of } \\
\text { the scapula }\end{array}$ \\
C & Ideberg type IV & $\begin{array}{l}\text { Sustained an undisplaced } \\
\text { fracture to the greater } \\
\text { tuberosity and gelnoid fossa } \\
\text { exiting laterally }\end{array}$ \\
& Ideberg type II & $\begin{array}{l}\text { Transverse fracture through } \\
\text { the glenoid exiting the } \\
\text { scapula medially and laterally } \\
\text { AC joint dislocation with } \\
\text { widening of the }\end{array}$ \\
D & Ideberg type Vacoclavicular gap \\
E & Rockwood IV & \\
& &
\end{tabular}

to be injured is $30-39$ years. $^{2}$ We found that complex injuries to the shoulder girdle involving disruption of the four-bar linkage were more common in older cyclists. These injuries are more difficult to treat, although our group achieved good postoperative results. The papers reviewed indicate that appropriate protection and limiting exploits to those within the cyclist's ability have been shown to reduce the injury rate in these patients. $^{12}$

This area of sports medicine is relatively underresearched with most papers looking at head injury and helmet use. More information regarding shoulder fractures sustained during mountain bike accidents should be collated, so that colleagues have a greater understanding of this area and are better able to treat these patients. Medium-term and long-term results of operative treatment of these complex shoulder girdle injuries in all sports could help improve the understanding the management of these particularly difficult injury patterns. Improving or adapting protective equipment to specifically protect the shoulder girdle may be useful.

Twitter Follow Matthew Lea at @matthewlea87

Competing interests None declared.

Patient consent Obtained.

Provenance and peer review Not commissioned; externally peer reviewed.

Data sharing statement No additional data are available.

Open Access This is an Open Access article distributed in accordance with the Creative Commons Attribution Non Commercial (CC BY-NC 4.0) license, which permits others to distribute, remix, adapt, build upon this work noncommercially, and license their derivative works on different terms, provided the original work is properly cited and the use is non-commercial. See: http:// creativecommons.org/licenses/by-nc/4.0/

\section{REFERENCES}

1. Carmont MR. Mountain biking injuries: a review. Br Med Bull 2008;85:101-12.

2. Aitken SA, Biant LC, Court-Brown CM. Recreational mountain biking injuries. Emerg Med J 2011;28:274-9.

3. Kim PT, Jangra D, Ritchie $\mathrm{AH}$, et al. Mountain biking injuries requiring trauma center admission: a 10-year regional trauma system experience. J Trauma 2006;60:312-18.

4. Kronisch RL, Pfeiffer RP. Mountain biking injuries: an update. Sports Med 2002;32:523-37.

5. Carmont MR, Daynes R, Sedgwick DM. The impact of an extreme sports event on a district general hospital. Scott Med J 2005;50:106-8.

6. Goss TP. Scapular fractures and dislocations: diagnosis and treatment. J Am Acad Orthop Surg 1995;3:22-33.

7. Goss TP, Busconi BD. Scapula fractures: surgical principles and treatment. In: Fu FH. Ticker JB, Imhoff AB, eds. An atlas of shoulder surgery. London: Martin Funitz, 1998.

8. Goss TP. Fractures of the scapula: diagnosis and treatment. In: Iannotti JP, Williams GR, eds. Disorders of the shoulder: diagnosis and management. Lippincott Williams \& Wilkins, 1999;597-637. Ch. 23

9. Ideberg R, Grevsten S, Larsson S. Epidemiology of scapular fractures. Incidence and classification of 338 fractures. Acta Orthop Scand 1995;66:395-7.

10. Rockwood CA, Williams GR, Young DC. Acromioclavicular injuries. In: Rockwood CA, Green DP, Bucholz RW, et al. Fractures in adults 4th ed. Vol I. Philadelphia, PA: Lippincott-Raven 1996:1341-3.

11. Nelson NG, McKenzie LB. Mountain biking-related injuries treated in emergency departments in the United States, 1994-2007. Am J Sports Med 2011;39:404-9.

12. Ruest $\mathrm{N}$, Nguyen $\mathrm{M}$, Embree $\mathrm{T}$, et al. Mountain bike terrain park injuries: an emerging cause of morbidity. $\mathrm{Br} J$ Sports Med 2011;45:312. 